\title{
Research on the Advantages and Feasibility of Music Headset Live
}

\section{Cai Wang}

Registered NO. 11339884

The Education University of Hong Kong, April, 2020

\begin{abstract}
Our team adopts a new form of live music, which is to enjoy live music with headphones. This new form of analysis can combine the advantages of live music and recorded music. The audience can adjust the volume, reverberation, etc. according to their needs. This high-quality new format can attract the audience to know some truly outstanding original musicians, bands and music, not just through the "star effect". In addition, Our team studies the great commercial value of this new form of musical performance. Audiences can rent or buy high-quality headphones to listen to high-quality concerts, which means that practitioners can cooperate with some headphone brands. At the same time, the live performance was recorded as a separate track at the end. Mixers will make them into recordings, and practitioners can collect royalties from them.
\end{abstract}

Keywords: music headset live; new form; stage performance; Immersive; higher-quality

\section{Introduction}

The live music venue has long been regarded as a space of critical importance in the base to himself to experience. (Bennett \& Rogers, 2016). The music performance venues for popular music are mostly the concert hall and live house. But they tend to be large in space or noisy in the environment (Gibson \& Homan, 2004). The venue and environment for this kind of performance is very suitable for rock and roll and some other loud music. While for some folk music, jazz, electronic music and a lot of relatively quiet original music, the singer's inner exquisite emotion is expressed by the slight change of the breath intensity and the slight trembling of the voice. Large Space and noisy environment can greatly affect the concentration of performers and the audience's reception of musical details during the performance.

Therefore, we wanted to give people who love these kinds of music a new form of live music, that is, enjoying live music by headphones. The new form could combine the advantages of live music and recorded music. The audience can adjust the volume, the reverberation and so on according to their own needs. At the same time, the singers and musicians will each wear a pair of earphones, so that they can hear the audience talking and interact with them at any time. This form can greatly improve the audience and performers' concentration on the performance of the music itself, so as to avoid the phenomenon that the audience focuses on shooting videos during the performance. In addition, this new form with higher quality could attract the audience to know some truly excellent original musicians, bands and music, not just through "star effect".

On the other hand, this new musical performance form also has great commercial value. Audiences rent or buy higher-quality headphones for higher-quality concerts, which means practitioners can work with some headphone brands. At the same time, the live performance is recorded as a separate track and finally, the mixers will make them into recorded audio, from which practitioners can collect royalties.

Copyright (C) 2020 Cai Wang

doi: $10.18282 /$ le.v9i6.1345

This is an open-access article distributed under the terms of the Creative Commons Attribution Non-Commercial License

(http://creativecommons.org/licenses/by-nc/4.0/), which permits unrestricted non-commercial use, distribution, and reproduction in any medium, provided the original work is properly cited. 


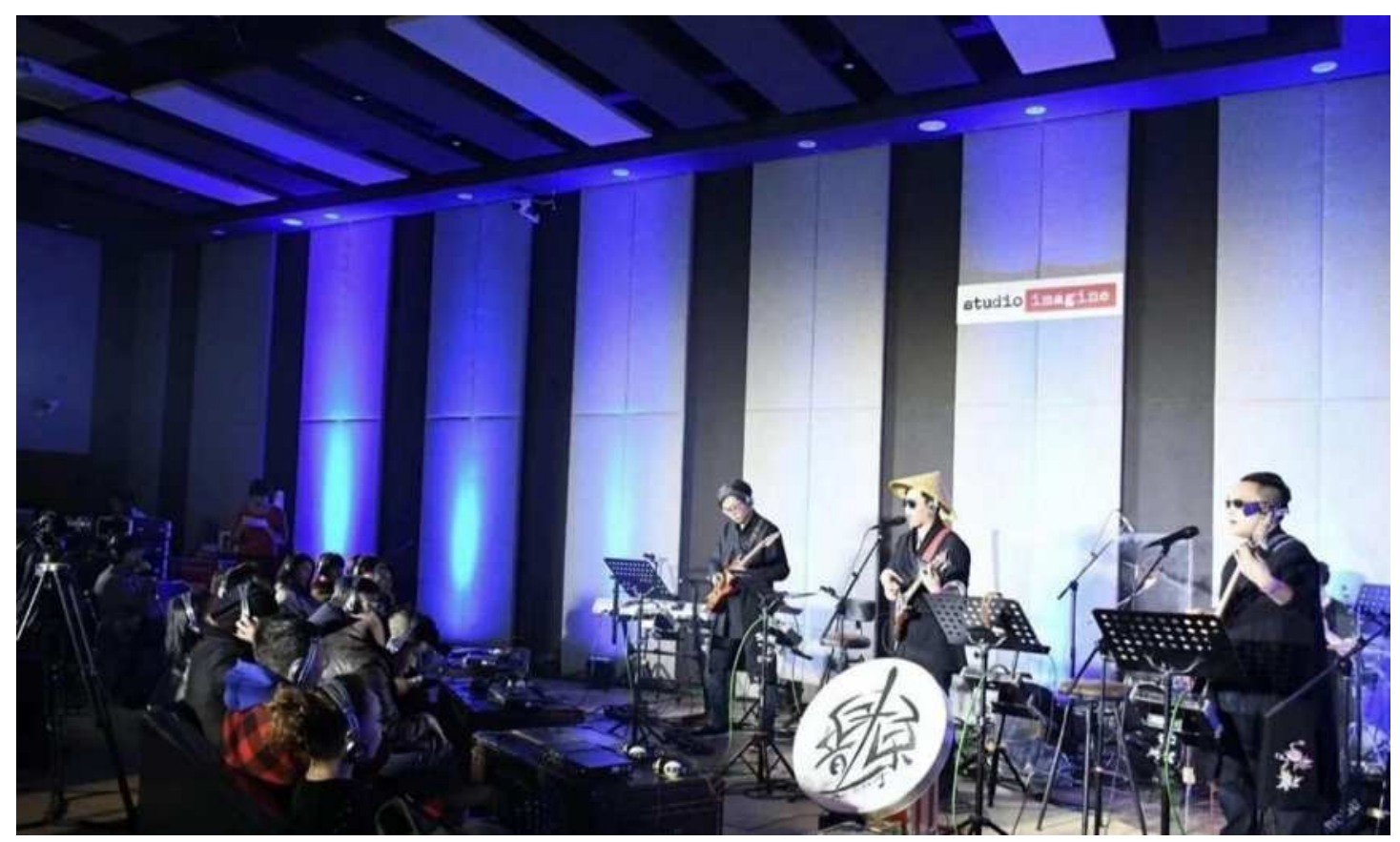

Figure 1.1 Music by Young Music Headset Live Picture 1

\section{Mission}

1. The higher quality of music hearing itself

2. Promote new forms of stage performance

3. Enhance sound representation in performance

4. Improve enjoyment of the performing arts and accessibility

5. Stimulate the audience's curiosity and understanding of performing arts

6. Show new-generation musicians and musical works

7. Broaden the music market for college student

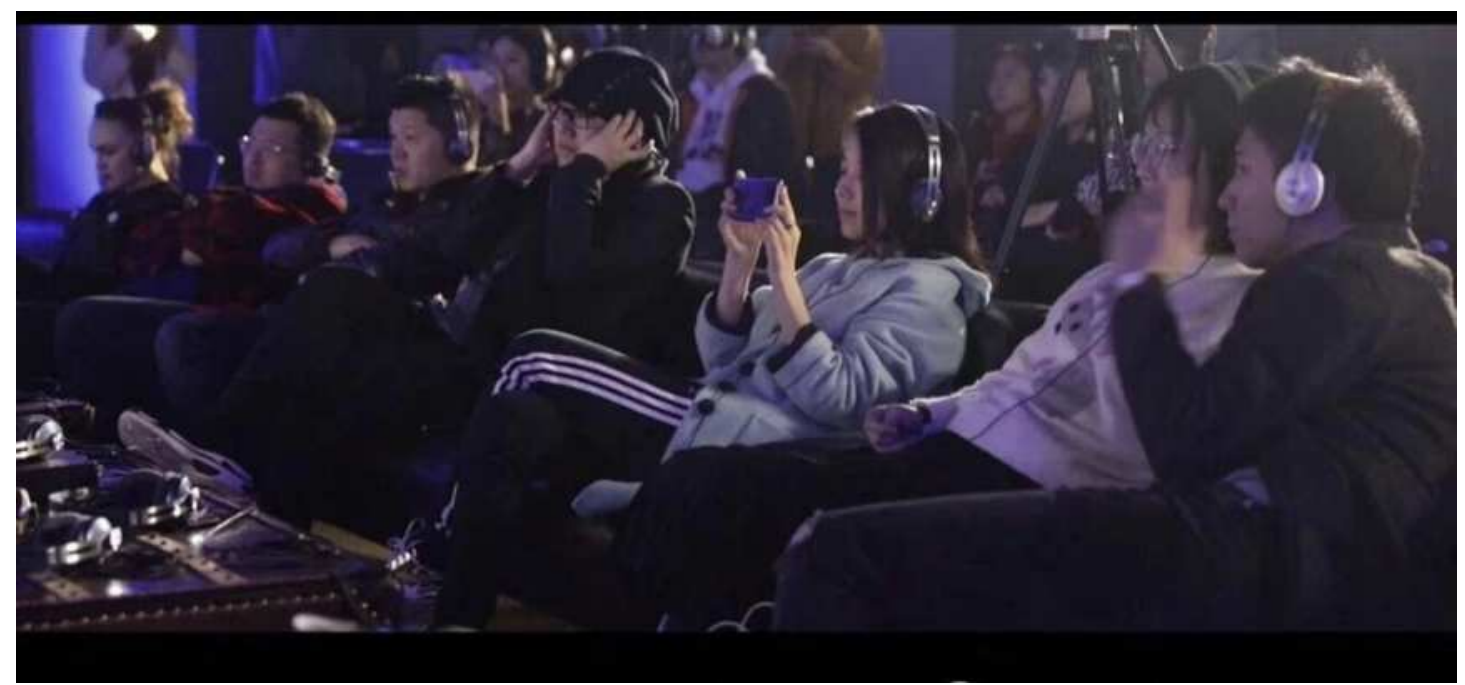

Figure 2.1 Music by Young Music Headset Live Picture 2

\section{Vision}

1. Reduce the star power in the music market 
2. Increase the artistic value of music

3. Make China's first truly high-quality live digital music---Live CD

4. Increase company awareness

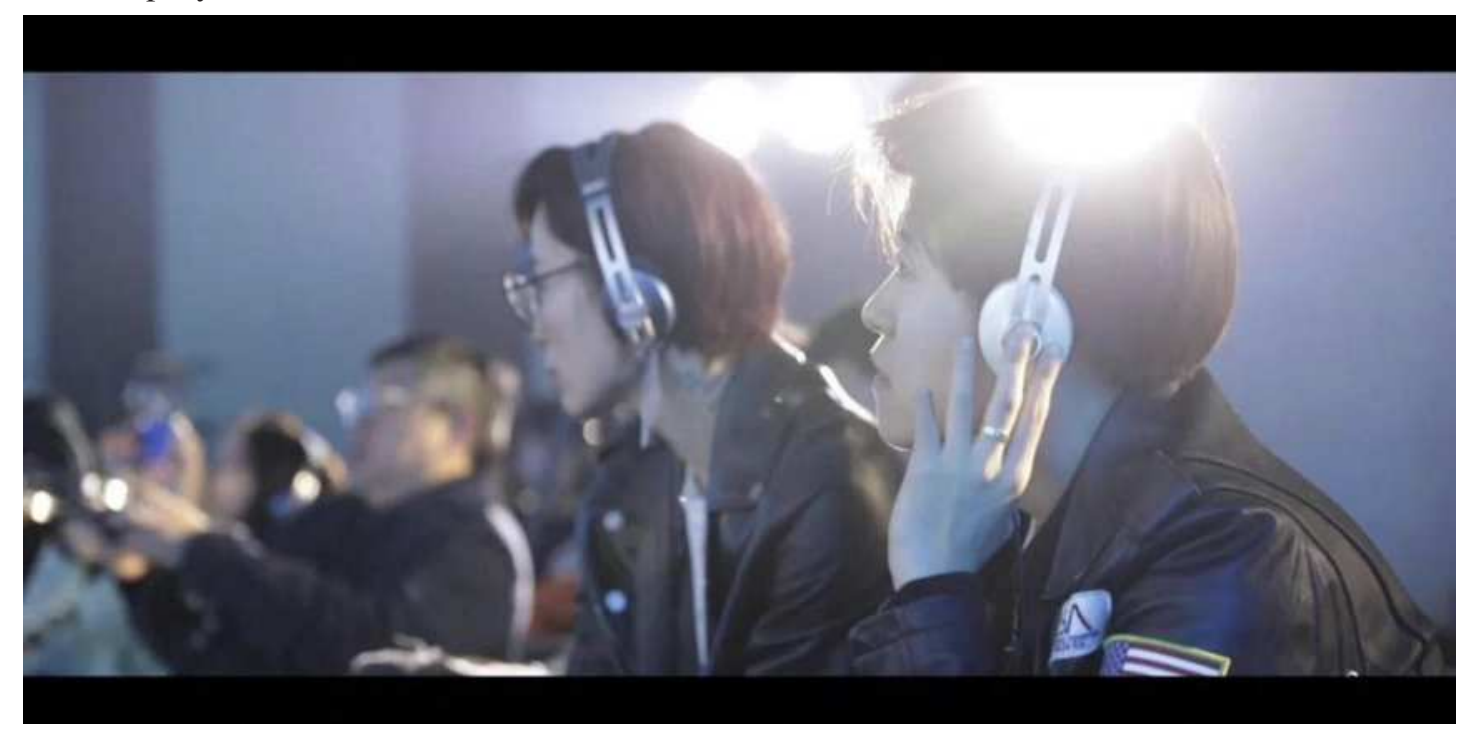

Figure 3.1 Music by Young Music Headset Live Picture 3

\section{Project Content}

Nature: Live

Period: On the first Saturday of every month or themed events, such as Valentinus's day

Venues to be used: A recording studio in Beijing

Pricing: 98RMB; 158RMB; 398RMB (Different fares provide different earphones)

Audience size: Less than 30 people

Duration: About 1 hour

Target Audience: Having a certain economic foundation and have higher requirements for the quality of music

Core Activities and Services: Our group's project plan is to host an original music headset live in a recording studio. Music live house and concert halls are common venues for music performance. Audiences enjoy the musical works of musicians and bands through speakers. The earphone scene is different from the gorgeous noisy stage. Using headphones instead of audio can eliminate the complicated dance lights and stage performance, return to the essence of music and enjoy the album-quality music scene.

Online Propaganda: Advertisement on the social APP

Offline Promotion: Co-branding, the poster on the university campus

\section{Timeline}

Form 1.1 Music by Young Music Headset Live Timeline

\begin{tabular}{|c|c|}
\hline Project application Time & June 1,2020. \\
\hline Invite GuestlContact partners & July, 2020 \\
\hline Propaganda Period & August 15-September 1,2020 \\
\hline Ticket Time & August 15-September 12,2020 \\
\hline Show Time & September 12, 2020 \\
\hline
\end{tabular}




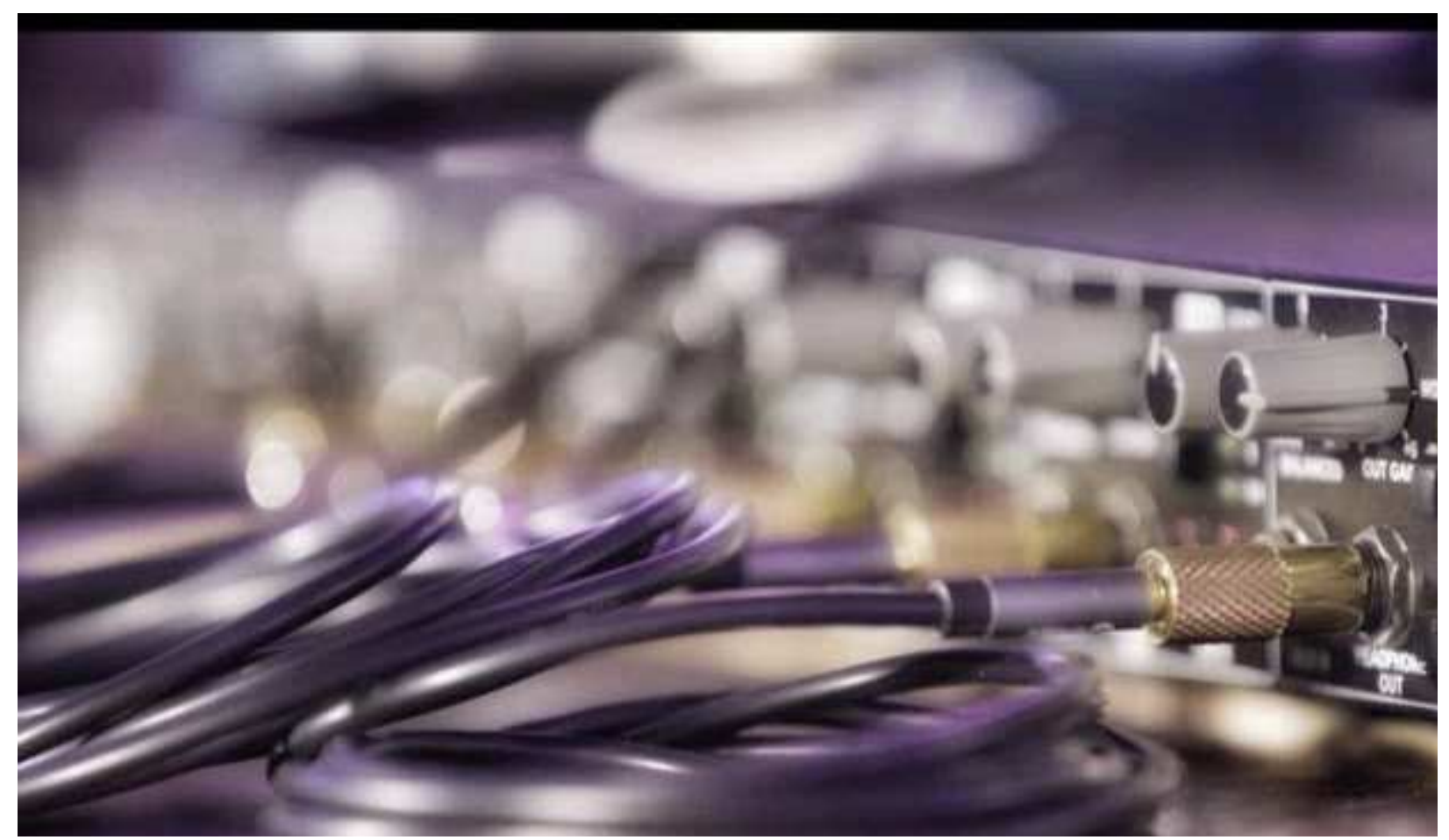

Figure 4.1 Music by Young Music Headset Live Picture 4

\section{SWOT analysis}

\subsection{Strengths}

Using headphones as an intermediary to watch the concert will bring many different experiences to audiences. First of all, it is a new and interesting way to watch music performance rather than a traditional way to watch a performance. Audiences listen to the sound and watch a concert through their ears. Secondly, for the presence of some original music, gorgeous stage and shocking sound are not the best way, because these works do not have too many elements of stage performance, and they have higher requirements for the quality of music hearing itself. Finally, due to the details of this original music are very important, when they are presented live, they could reflect their emotions and connotations better when they are enlarged. Music headphone's live house performance is a very novel way for young people who like to watch the concert. Many people who are fond of watching the concert have higher requirements for it now. This form of concert fits their need very well.

\subsection{Weaknesses}

Some people think watching music performance with headphones is not very comfortable. In their opinions, listening to music performance should use their own ears rather than headphones. These audiences are a little traditional, they are not willing to accept a new way of watching music performance. So, I think it is the weakness of music headphones live house performance.

\subsection{Opportunities}

According to the calculation by the research group of China Innovation Index Research of the Social Science and Culture Department of the National Bureau of Statistics, China's innovation index reached 212.0 in 2019, an increase of $8.6 \%$ over the previous year, which doubled from the past. In terms of different fields, the ratios of innovation environment index, innovation input index, innovation output index and innovation effectiveness index all showed different degrees of growth. It shows that China's innovation environment continues to be optimized, innovation investment continues to increase, innovation results are gradually showing, and scientific and technological strength and innovation capabilities have reached a new level. With the development and progress of science and technology, there are more and more intermediary and equipment can be used to listening to music. Headphones as tools for 
people to listening to music are used very comprehensively. Nowadays, with the development of the economy, more and more people are willing to watch concerts. Some of these audiences have not to be satisfied with watching traditional concerts. They hope to find some newer and more interesting way when watching concerts, which provides the possibility for the appearance of the music headphones live house performance. There are more high quality and multifunctional headphones in the market, people have the freedom to choose what headphones they like to use when watching music headphones music live house performance. As sponsors of it, we could also provide for audiences appropriate headphones when they watching the headphones music live house performance.

\subsection{Threats}

The popularity of headphone's music live house performance is not known by most people, only young audiences know this way of watching the concert. Therefore, the headphone's music lives house performance needs to increase publicity. On the other hand, the sponsors need to buy and provide many high-qualified and appropriate headphones for audiences, so the cost of it is much than the traditional concert.

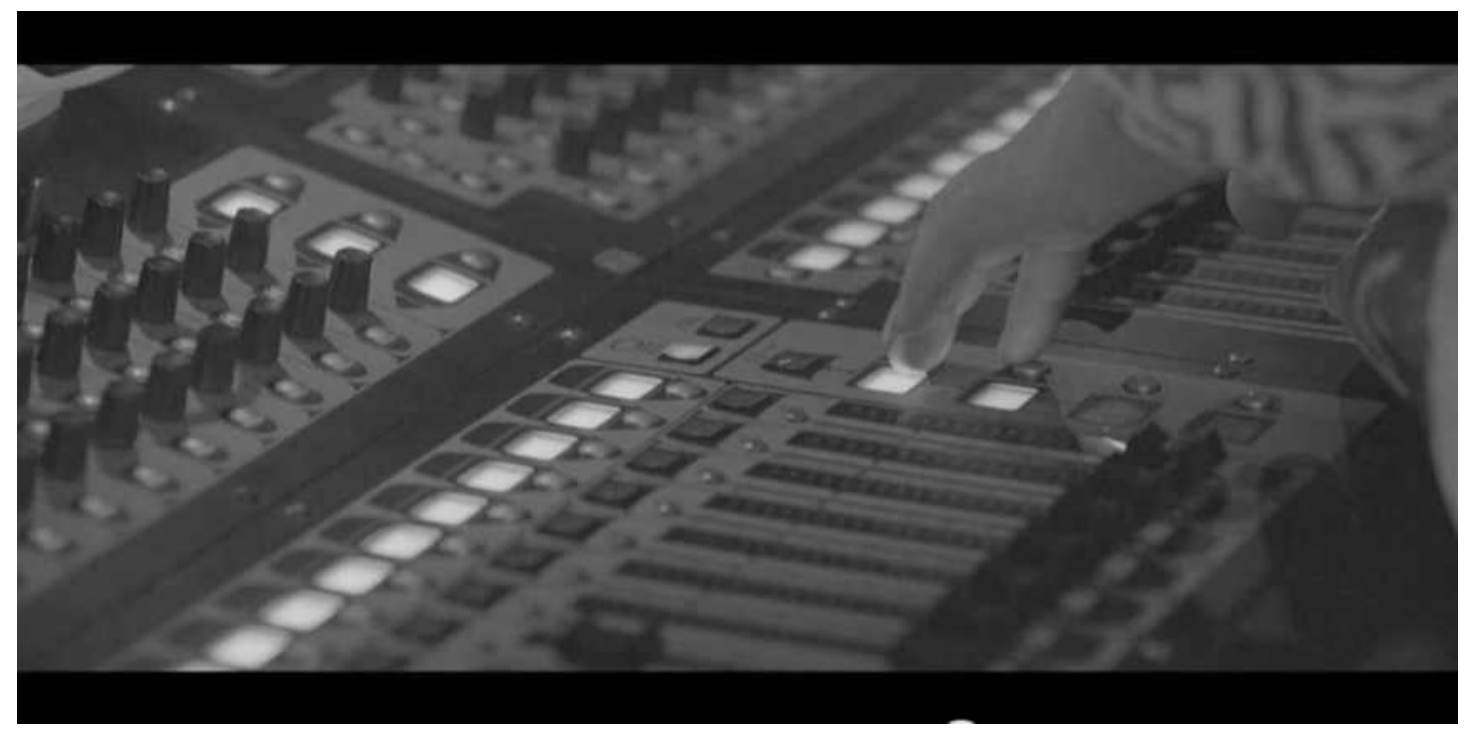

Figure 5.1 Music by Young Music Headset Live Picture 5

\section{PEST analysis:}

\subsection{Politics}

The Chinese government put Opinions of the CPC Central Committee on Prosperity and Development of Socialist Literature and Art and many other policies related to the art filed to support and promote the development of art culture career these years. In March 2018, entrusted by the former State Administration of Press, Publication, Radio, Film and Television, the people's music publishing house officially launched the "national music industry award program for outstanding projects". The programme evaluates and rewards the creation and production of original music, the publication and dissemination of musical masterpieces, the application and integrated development of new technologies in music, and other relevant industrial projects. At the same time, it encourages the creation, dissemination and industrial integration of excellent music culture, and summarizes and promotes the achievements of the project to guide and promote the sound development of the music industry. Headphones music live house performance accords with the novel requirement of cultural policies. It is a new concert format. Therefore, this kind of concert format is supported by government policies.

\subsection{Economy}

1. Since China's reform and opening up in 1978, its economy has grown at an average annual rate of $9.72 \%$, making it the fastest-growing country in the world.

2. Beijing residents have a large proportion of cultural entertainment. 
3. The output value of the domestic digital music market continues to grow, so music has potential development space.

\subsection{Society}

Attending cultural activities is a part of people's daily life. More and more citizens pay attention to themselves' cultural literacy. Watching the concerts, visiting the art exhibition and so on are becoming one of the daily things for many people. According to figures released by the China performing arts association ,the total number of concert held in China rose from about 1,400 in 2013 to about 2,800 in 2018, with a compound annual growth rate of $14.9 \%$.As a major revenue source for concerts and a key indicator to measure the development of China's concert preparation market, the box office of Chinese concerts is also growing. In 2013, the total box office of Chinese concerts reached 2.1 billion yuan, which reached 4.4 billion yuan by 2018, with an average annual compound growth rate of $15.9 \%$. They are eager to appreciate something newer and more interesting in the life of art. Headphones music live house performance are popular with audiences who are fond of this new concert format, which will bring them different experiences in listening to music at the concert.

\subsection{Technology}

The on-site technology of the earphone is as advanced as it is capable. This event is held in a large recording studio.

First of all, musicians and performers can use monitor headphones as their own monitoring equipment on the stage and can debug the effects on their own devices according to their singing habits or playing habits, but it does not affect the effects heard by the audience. Traditional ear loops cannot be adjusted by themselves, especially if they cannot be adjusted, but the headphones can be used on the spot, not only on the device but more importantly, because the headphones are placed outside the auditorium, the performers will have unprecedented monitoring Experience. The performer can also ask the live tuner to change his listening mode to the audience mode so that he can hear his own performance in the audience 's headphones, which breaks the traditional musician or musician on the stage. The performance methods on the show have created new monitoring and experience for bands and musicians performing on stage, which is conducive to the display of their musical works.

Secondly, not only can the Secondly, not only can the music effects heard by the audience be completed by the onsite tuner, but the audience can also use the amp device on the seat to adjust the effect in the headphones according to their own preferences on the seat. The audience can simply perform some basic operations, such as volume, phase, reverb, delay, etc, and they all complete according to their own needs. At the same time, the on-site staff is equipped to assist the audience and the musicians on stage to debug the equipment and strive to personalize the music on-site listening experience.

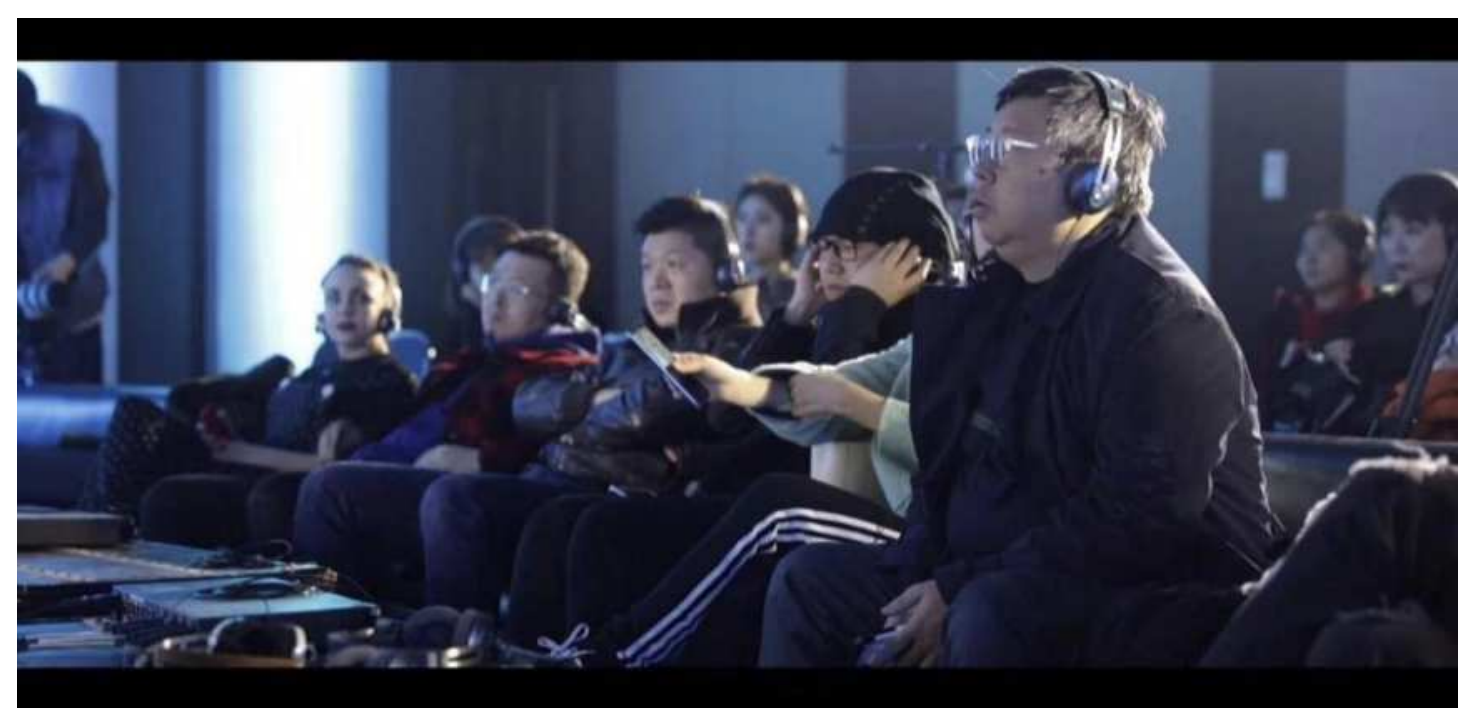

Figure 6.1 Music by Young Music Headset Live Picture 6 


\section{Impact}

For performing artists, it can satisfy their desire for the ultimate and perfect artistic effect. Through the technical support of earphones and the meticulous recording in the recording studio, the sound effect achieved can achieve the effect that the artist hopes to convey to the audience as much as possible.

At the same time, the perfect radio and playback technology has higher requirements on the technical level of artists. Any slight accident will be magnified through the earphone and captured by the audience. Therefore, it can promote continuous improvement and high standards of artists.

Musicians will also get a boost. In each live performance will retain the live effect, the performance can be made into the copyright, the incomes from the copyright will increase.

It provides a platform for some truly capable emerging artists to allow the audience to receive the most authentic and unreserved details and high quality of music, so as to be familiar with the audience and improve their own popularity and influence. Impress the audience and gain more fans.

Raise public awareness of the importance of musical diversity and musical quality pursuits in a healthy music ecosystem. In real life, people have little access to "lossless quality" music, and due to copyright and platform restrictions, even if the expensive equipment is prepared, what is really obtained is the compressed sound effect. Our project provides a good place and conditions for people with high artistic quality and requirements, as well as headphones and audio enthusiasts so that they can enjoy top-notch audio effects on the basis of only spending a little money. Therefore, our project can attract a stable and loyal target group. At the same time, because we provide highquality music effects, it will also attract a group of music lovers with high requirements for music.

The improvement of the performance requirements of the performers can better develop a higher level of art. The headphone scene is undoubtedly beneficial to the development of art. Firstly, the requirements for high-quality music listening represented by this project will promote the development of musical art from the mass and popular level to the direction of higher quality and higher level.

Since we are a niche project, we are more inclusive of the music types and groups corresponding to the niche. For example, for some original music works, our project provides them with an opportunity to show themselves in the form of one band three performers. Promoted the development of niche music genre.

This project strengthens the interaction and connection between the producers of earphones and audio equipment and the audience, and exchanges increase the value of the contact in various industries, bringing potential derived business value.

\section{Risk assessment}

\subsection{Risk}

1.Participants: Audience physical and psychological tolerance.

2.2. Equipment and facilities: Electric leakage, Catch fire.

\subsection{Solution:}

1.According to the type of music on-site, the publicity indicates that it is inappropriate to participate in the crowd, and the staff reconfirmed before the audience entered the venue.

2.Ensure the normal use of emergency entrances, broadcasts, and environmental ventilation systems. All equipment with potential safety hazards will be left under the care of the person. If an accident occurs, two security guards will use the evacuation guide signs to let the audience leave the venue from the evacuation passage.

3.All staff will have relevant training and drills. At the same time, we will guarantee the safety of food, drinking water and medical aid. As a profitable place, the recording studio has the qualification and basic guarantee to deal with fire and other unexpected situations.

\section{Financial Status}

The most important thing for us is to control the cost of the headphone scene because this is a completely new form 
of the music scene, which needs continuous exploration. We envisage the following five main profit models.

The first is ticket income. We set the ticket price at 90 to 300 Hong Kong dollars. One is ordinary student tickets, the other is ordinary appreciation tickets, and the other is VIP exclusive tickets. These three tickets enjoy different services and live music experience.

Student tickets enjoy the same treatment as ordinary tickets. They are all headphones used in the back row of the auditorium and use medium-quality headphones. VIP tickets are high-end fever monitor headphones, sit on the sofa to enjoy music, a total of 40 tickets to 70 audiences of the three types of tickets. There are 35 to 50 ordinary appreciation tickets and 15 to 20 VIP tickets. In this way, the total income of one ticket is about 7600 RMB to 13500 RMB. We can also make group tickets and discount tickets. Once a month, you can earn about 100,000 Hong Kong dollars a year.

The second method is advertising and sponsorship income. This is determined according to the content of our performance and the objects covered. In order to control costs, we try to choose musicians and bands that do not require performance fees or musicians and bands who only need to reimburse carriage fees. We find these musicians and bands from college students. Among college students, there is a well-known brand in the Mainland called Music by Young. This brand is the most influential college student music brand in China. In 2019, the National College Student Music Alliance was formally established. With 28 universities in Beijing and 15 universities in Nanjing as the core, it has brought together more than 100 university music clubs across the country. As of June 2019, there have been more than 100 large and small campus music performances held, and almost all bands (nearly 200) of all university clubs in Beijing have performed on the poplar stage. It has the largest group of college student musicians and the influence of college music lovers. And, what they need most is for the musicians to be promoted, promoted and cultivated. The musicians will be very willing to cooperate with us to let the young musicians perform on the headphones. Of course, the quality of these college students' performances must also be strictly controlled by us. The headphones only welcome high-quality music works. With their musicians and their support as a party, we can pull sponsorship from the perspective of the college student market. All products for college students may become our potential sponsors. For example, in terms of music education for college students, examinations for college students, fitness, daily necessities, food, beauty, cosmetics, etc., will all become our sponsoring partners. In terms of sponsor income, we provide comprehensive income feedback to the sponsors from the three stages of the event: the early, middle and late stages. Facing the college student market, expanding their influence. Especially on the spot, we can open a promotion or raffle link for the sponsor. The prize for the raffle can be their own prize, or it can be our ticket for the next performance. For us, it is also publicity, which can stimulate re-consumption and is conducive to the continuity of consumption. At the same time, we can use the audience's self-media to allow spontaneous advertising for sponsors.

The third point is the form of sponsorship. We can either sponsor funds or replace resources. Then our headphone needs resource replacement. For example, we can design Sennheiser as the exclusive earphone supporter, and Sennheiser manufacturers provide us with headphones and amps as our on-site equipment. For them, we made an earphone promotion for them. Sennheiser can also sell its products on our site, and they can divide the profit of some of our product income. Perhaps the support can be enough for our staff to eat and ride.

At the same time, from a cost-saving perspective, the musicians and bands of college students mentioned earlier are the lowest cost, and some customer groups that can have their own radiance are doing two things at once. At the same time, in order to improve the level of our entire music and increase our fares, we can invite one or two famous people. Although celebrities are very expensive, we cannot directly invite celebrities, but invite their behind-thescenes producers to share with us the stories behind these celebrity songs. Promote star producers, start our event advertisements, and increase the value of events. It is relatively easy to replace resources with star producers. Since our other musicians are excellent talents from campuses without brokerage companies, producers can borrow this event to discover new generation musicians, which is really attractive. At the same time, because of the existence of star producers, it is also an incentive for college musicians. They are willing to show themselves for the possibility of more development in the future. Therefore, star producers can also mobilize the enthusiasm of college student musicians to participate in the live performance of headphones.

Regarding the sponsor, there is one more supplement. In terms of resource replacement, there are some businesses 
for college students, such as playgrounds and movie theaters. Their sponsorship may be in the form of tickets. As the organizer, we can try to sell these tickets or make up our own tickets, and these package tickets can increase our fare.

The fourth point is the copyright gains from the live music performance of the headphones. Because we are the site of original music headphones, the performers have the copyright of the songs, and we can ask them to grant us the copyright of the music or management rights of the performance on the premise of commercial rights under the premise of having the right to sign. Because the headphones are held live in the recording studio, the sound collection effect is excellent, and the music is split into the mixer, so we can get original music with higher sound quality. Over time, the operation of music copyright will also bring us a considerable amount of income.

Fifth, since the headphone scene is a new form of the music scene, it is a new exploration with great social value for the entire music industry and the spiritual pursuit of people's material culture. Therefore, we are investing in this In terms of, we can try to apply for some government art fund projects. To support us in doing this better. If stars can join in the future, for us, we can try to follow the economic route of stars and fans, and make the headphones live as a TV or Internet program, which is more influential and integrated into people's daily life. Let it not only be a popular leisure method, but also a kind of enjoyment of high-end music quality.

\section{Financial income}

As mentioned in the previous profit model, the estimated average revenue of each ticket is about 10,000 Hong Kong dollars, the sponsorship is expected to be about 30,000 Hong Kong dollars, the potential revenue of music copyrights is 2,000 Hong Kong dollars per song, and 10 songs are about 20,000 Hong Kong dollars. The total income is about 60,000 .

Form 2.1 Income statement of: A music headset live

\begin{tabular}{|c|c|}
\hline \multicolumn{2}{|c|}{ Income statement of: A music headset live } \\
\hline as of: 05/06/2020 & Amount in CNY \\
\hline Cash - Sponsor & 20000 \\
\hline Receivable for tickets & 8900 \\
\hline Receivable for product sponsorship(market value) & 60000 \\
\hline Payable for staff & -350 \\
\hline Payable for renting earphone & -1050 \\
\hline Payable for performing musician & -2000 \\
\hline Real estate mortgages (recording studio) & -2000 \\
\hline Payable for advertising & -500 \\
\hline Other budget (dinner, celebration,etc.) & -1000 \\
\hline EBITDA & 83000 \\
\hline EBIT & 83000 \\
\hline Tax & -4600 \\
\hline NET INCOME & $78,400.00$ \\
\hline
\end{tabular}

\section{Financial expenses}

Musicians' horse and carriage fees are controlled within 3,000 Hong Kong dollars, and the staff mostly use volunteers to replace them with tickets for the next performance. There is no cost for headphones, and the studio cost is not calculated. Publicity materials and online media promotion execution costs are controlled within 2000. A total of 7000 RMB.

\section{Key staff/artistic personnel}

The main personnel involved in this activity include organizers, art performers, special guests, news media personnel, partners and security personnel.

The organizer of this performance needs to be responsible for administration, field affairs, ticketing, reception, and revenue and expenditure settlement. Administrative staff need to sign corresponding contracts with venue vendors, 
equipment leases, and planned performers. Field staff needs to be responsible for the layout of the performance site and the formulation of security personnel. Ticketing staff needs to determine the fair distribution based on on-site seats and do a good job of giving tickets to partners. The staff responsible for reception needs to do the reception work of artists, guests, media and partners, such as pick-up vehicles, rehearsal reception, etc. The staff responsible for revenue and expenditure settlement needs to cooperate with the financial personnel to do all the revenue and expenditure settlement work involved in the activity.

Art performers participating in the live performance of headphones can invite some young original musicians. For example, musicians from Young Music, the strongest original music brand of college students in China. Young Music has the strongest original musicians of college students in China today. Such activities can give these powerful young musicians the opportunity to show their musical works.

Original music headphones will also invite special guests, such as music producers of some star singers. Inviting star music producers can not only attract more audiences but also provide better cooperation opportunities for young performers.

Brand partners who provide sponsorship for this event can use the form of resource exchange to achieve a winwin situation and achieve sustainable long-term cooperation. The organizer of the event can provide free tickets for the equipment sponsored partners of this show or advertise for the brand. This way can not only reduce the budget but also achieve a win-win effect.

The people participating in this event also have media. Some well-known media in the music field can be invited to report on this music scene and interview art performers and special guests. Through media reports, the effect of publicity can be increased.

Finally, security personnel, they are mainly responsible for the on-site order maintenance and fire safety inspection of activities and are responsible for the safe evacuation at the beginning and end of the live show.

\section{Conclusion}

As a new form of music scene, Music headset live improves the quality and effect of music, and truly returns to music itself. This form not only allows performers to achieve perfect performance, but also allows listeners to understand truly high-quality musical works. Music headset live breaks the traditional live mode and promotes the diversified development of the music scene. This kind of cost-effective music scene will become the first choice for people who really love music and become the future development trend of music scene.

\section{Reference}

1. Bennett, A., \& Rogers, I. (2016). In the Scattered Fields of Memory: Unofficial Live. Music Venues, Intangible Heritage, and the Recreation of the Musical Past. Space and Culture, 19(4), 490-501.

2. Gibson, C., \& Homan, S. (2004). Urban Development, Live Music and Public Space: Cultural performance and the re-making of Marrickville. International Journal of Cultural Policy: Urban Space and the Uses of Culture, 10(1), 6784. 